\title{
CSI (Crash Scene Investigation) Project: Integrating Writing and Disciplinary Thinking in an Engineering Dynamics Class
}

\author{
Janice Miller-Young, Ph.D., P.Eng \\ Associate Professor, Dept. of Mathematics, Physics \& Engineering \\ Mount Royal University \\ jmyoung@mtroyal.ca
}

\begin{abstract}
This paper details an inquiry-based project, and how the technical report writing and disciplinary thinking components of it were incorporated into the weekly activities of a traditional engineering dynamics class. With the development of an appropriate problem, the project structure could be incorporated into any class. Techniques for marking engineering reports without significantly increasing instructor workload are also discussed.
\end{abstract}

\section{Introduction}

A main focus in engineering education is to teach students to solve open-ended and underdefined problems, which requires analyzing and synthesizing the best available data, making assumptions and simplifications when necessary, and recognizing the limitations of an analysis. Typically, engineering design projects are expected to engage students in developing these skills, but design projects are often limited to specific design courses and it is hard to find space for them in other content-heavy courses. Therefore, an inquiry-based learning project was developed for a first-year dynamics class which was designed to scaffold students as they developed these skills.

The design of this project was influenced by several key sources. Felder and Brent [1] describe student-centered instruction as leading to increased motivation to learn, greater retention of knowledge, deeper understanding, and more positive attitudes toward the subject being taught. Some techniques for student-centered instruction which were incorporated into this project include having students confront problems before they are given all the materials needed to solve them, and replacing some lecturing with participatory exercises done by individuals or small groups in class.

Bean [2] describes designing interesting problems as one of the teacher's chief tasks and states that integrating writing and critical thinking activities into a course increases students' learning while teaching them skills for posing questions, proposing hypotheses, gathering and analyzing data, and making arguments. Some principles for supporting critical thinking include designing courses that are assignment-centered rather than lecture-centered, requiring students to formulate and justify their ideas in writing or other appropriate methods, using problems as the point of entry into a subject and a source of motivation for sustained inquiry, and balancing challenges to think critically with support tailored to student needs [3]. In coaching writing and critical thinking, Bean [2] also suggests critiquing sample solutions and papers, sharing your own thinking processes, breaking long assignments into stages, and stressing revision and multiple drafts. All of these principles were considered in the development of this project.

\section{The Project}

Students analyzed a car accident and wrote an engineering report detailing which car was at fault and to help determine whether a passenger was wearing her seat belt. The problem was solved in stages as students learned the necessary dynamics concepts, and the stages were incorporated into their regular weekly assignments so that the project did not add to the overall workload of the course. The report was also written in stages and iterations in order to improve the students' technical writing and disciplinary thinking skills and provide formative feedback. The project was worth $10 \%$ of the overall course mark. 
When the project was introduced, students were presented with the following text:

You have been called upon as an expert witness to analyze a car accident. The passenger of the bullet car, Faye Kinitt, is suing the driver of the bullet car, Lou Scannon, for her injuries. The lawyer for Mr. Scannon would like to know whether or not Ms. Kinnitt was wearing her seat belt at the time of the accident, as she claims. This will involve consulting a forensic engineering and a physician. Your job as the engineer is to estimate the speed at which she would have hit her head if she had been wearing a seatbelt.

The lawyer requests a full report summarizing your calculations and reasoning by the end of term. Excerpts from a police report are attached (Appendix A.)

\section{Project Objectives}

To solve a real, complex engineering problem using the concepts presented in this course

To learn that real-life problems are typically openended without a unique solution, unlike the problems in textbooks.

To use critical thinking skills to determine what data is required and appropriate to solve the problem, and to justify your analysis.

To be able to explain the necessary mechanical principles in everyday language that a non-engineer can understand, as well as by using calculations and diagrams.

To justify your decision in a concise and persuasive technical report.

\section{Project Timeline}

The problem will be broken down into components corresponding to material presented in class. These components will be incorporated into the weekly assignments.

A list of topics includes: energy, impact and momentum, moments of inertia, rigid body kinematics, rigid body kinetics (see the course outline for approximate dates for these topics.)

Shortly after each part of the problem is assigned, there will be a class discussion about what additional information is required to solve the problem, at which time this data will be provided by the instructor.

The analysis and discussion section (including corresponding appendices, see report format, below) for each part of the problem will be due 2 weeks after that part is assigned.

\section{Project Assessment}

Note that, as in real life, there may not be a single right answer to this problem. Your work will be marked more on the quality of evidence and reasoning you provide to support your argument. (30\%)

Assumptions and calculations (20\%)

Report organization and quality of writing (30\%)
Grammar and spelling (20\%)

For each submission over the semester, reasoning and calculations will be given a mark at that time (worth 50\%), however only comments will be provided for your writing. This feedback is intended to give each student a chance to improve their writing, and then compile and submit the entire report at the end of the semester for the remaining $50 \%$ of the project mark.

Please note that general comments will be made about tone of writing, organization, and clarity of logic, however spelling and grammar mistakes are the responsibility o the student. An ' $\mathrm{X}$ ' will be placed beside each line with a spelling or grammar mistake and students are responsible for finding and fixing those mistakes themselves.

\section{Project stages, responses and feedback}

\subsection{Part 1a - initial problem analysis}

On a regular assignment, shortly after particle kinetics, impact and momentum had been covered in class, the following question was given:

In order to figure out of Faye Kinnitt was wearing her seatbelt, you will first need to have an idea of the change in speed of the bullet car (the Jeep YJ) during the impact. Tell me (in a sentence or two) how you plan to solve for the change in speed, and list the additional data you need to solve.

Most students answered that they needed the masses of the vehicles and any cargo, the coefficient of kinetic friction between the tires and the road, and the coefficient of restitution. A follow-up discussion in class involved a conversation about whether the mass of the occupants in each vehicle would significantly affect the calculated velocity change, and whether or not the coefficient of restitution would be a reasonable value that could be researched in "real life.”

\subsection{Part 1b - particle kinetics analysis}

On the next assignment, the following question was given:

The first section of your analysis (written description plus calculations in an appendix) involves figuring out how fast Lou Scannon was driving when he hit Wilma Cargough. Use the information given in the accident report as well as the following (and remember to state all your assumptions): the masses of each vehicle and occupant, as well as a typical coefficient of kinetic friction (with references) were provided. 
Most students calculated a velocity change correctly using the length of the skid marks from the accident report. However, few provided a comprehensive list of assumptions that had to be made to perform this calculation, such as that the impact was central, that all four wheels were locked during the skid, that the skid marks were visible and measurable for the entire length of the skid, and even that the road was flat.

My feedback on their writing mainly focused on formatting (for example, how they referenced the data in the Appendix), and developing a more professional writing style, as many of them used slang, hyperbole, (for example "By Using the Conservation of momentum Formula which is a formula that is proven to work by Engineers and Scientists all over the world such as our great knowledgeable professor...”) and tended to write their analysis section in a narrative form (for example, "First I used the coefficient of friction and mass to find the deceleration, then I calculated...”)

\subsection{Part 1c - particle work and energy comparison}

For this part of the assignment, I asked the class to look at the problem in a different way. The question on their assignment was worded as follows:

In accident analysis, crash test data is often used and the amount of crush damage from the accident vehicle(s) is compared to the results of the crash test in order to estimate the change in speed of the car(s). Crash tests performed on a 1987 Jeep Wrangler YJ found that, for an impact speed of $50 \mathrm{~km} / \mathrm{h}$, the crush damage to the YJ was about 17 in. when it hit a fixed concrete barrier. Using the principle of work and energy, discuss (in a short paragraph) how the crash test results can be used to support or not support your previous calculations. If not, which result do you think is more reliable? (A reference for the crash test was provided.)

The students definitely struggled with this question. In short, most of them had calculated an impact velocity of approximately $50 \mathrm{~km} / \mathrm{h}$ for the Jeep in the accident situation, where it sustained approximately 17 in. of damage, but both vehicles sustained damage and both slid after the accident. The crash test data then indicates that the Jeep in the accident must have actually been going much faster. Even after an inclass discussion of this comparison, many students did not report this argument clearly or even correctly, which indicated to me that their understanding or ability to apply the concepts of kinetic and potential energy was still weak. Further discussion was required after the assignment was assessed.
At this point students' writing was improving in terms of their professional tone, and my feedback focused more on using accurate language, for example not saying that "kinetic energy is converted into a force."

\subsection{Part I revisions and report draft}

By this time it was approximately the middle of the semester and I asked students to write an interim report based on what they had determined to date. Because almost no one had written a clear and correct answer to part 1c, I also gave them a chance to rewrite their analysis section of part I and get an improved mark for the evidence/reasoning component of their mark.

To minimize the marking time, their revisions were assessed as follows:

- If their written reasoning (accuracy and/or clarity) for Parts $1 \mathrm{~b}$ and $1 \mathrm{c}$ improved, they could receive up to a 2.5/30 increase in their original mark for each stage.

- If their original reasoning was marked as "incomplete", they could achieve a maximum mark of 20/30 for each stage.

- Feedback was given for report organization and ' $X$ 's were used to indicate grammar and spelling mistakes, but no mark was assigned at this time.

\subsection{Part II - rigid body kinetics analysis}

The last part of the analysis involved estimating the velocity with which Ms. Kinnit may have hit her head. Many assumptions had to be made for this analysis, which were discussed in class before the question was assigned. Assumptions included that her hip joint remains fixed relative to the vehicle, that her torso above the hip can be treated as a body that rotates freely about her hip, and that her initial torso position was vertical.

The last question on the last assignment was worded as follows:

Using the simplified model discussed in class, what is the velocity relative to the dashboard with which Faye Kinnit would have struck her head? Use the information given and state any assumptions you have made. Data provided included the radius of gyration of her torso about her hip, the torso mass and position of its centre of mass, and internal geometry of the vehicle.

By this time students' writing style had improved and they were much more thorough in providing a list of assumptions made. I gave minimal feedback at this 
stage, but if there had been more time left in the course, I would have liked to have spent some time on getting them to analyze the sensitivity of their results to the various assumptions they made.

\section{Lessons Learned}

\subsection{Student feedback}

Students initially were less than enthusiastic about having to do work other than solving textbook problems and memorizing equations for an exam, and some may have remained unconvinced towards the end of the semester when evaluations were completed. However, in the three semesters that I have run a variation of this project, I have only received one negative comment:

"CSI assignment was very confusing and wasted time that was needed to do problems."

Overall, end-of-semester feedback has been very positive and I believe the project ultimately engages students in the course material. Some examples of the positive feedback I have received include:

"My favourite part of the class would definitely be the CSI project. I did not think we had enough knowledge at this point to provide reasonable accurate calculations and reasoning for a case like a car accident. It was awesome to be able to do this, thank you."

"There are very few instructors that would take the time to review and give feedback as you did. Thanks.”

\subsection{Instructor reflections}

Overall, the project succeeded in facilitating the development of students' reasoning and writing skills, without taking class time away from covering content. I think it also demonstrated to them that real-life problems are complex and normally do not have a unique answer, unlike problems they typically solve from a textbook.
One of the most effective part of the assignment implementation seemed to be the feedback provided to the students on their writing and the chance for them to revise it in the final report at the end of the semester. Not only did they seem to appreciate the feedback, as indicated in the comment above, but the chance to revise certainly increased the attention they paid to the feedback given.

As an instructor, I really enjoyed the use of class discussions to teach the students how to approach problem-solving and formulating an argument rather than simply solving a perfectly constructed problem, as I so often do. Also, I did not find the marking of their reports noticeably more time consuming compared to marking solutions to standard textbook problems. The incorporation of the stages of the project into their regular weekly assignments was critical to keeping the marking load reasonable. However, this was a small class and I marked all of the students' work myself, so in a larger class and with multiple instructors there would probably be a slight increase in marking load per student due to the need to coordinate for inter-rater reliability.

In summary, this project structure could be incorporated into any class with the development of an appropriate problem. I think it would be most effective and rewarding if the expected outcomes of the assignment are clearly explained, if the problem does not have a unique solution (although this may increase marking time), and if the addition of such an assignment does not add to the overall work required in the course.

\section{References}

[1] Felder, R.M., and R. Brent. "The intellectual development of science and engineering students. Pt. 1: Models and challenges; Pt. 2: Teaching to promote growth.”, Journal of Engineering Education 2004, 93(4), pp. 269-77.

[2] J.C. Bean, Engaging Ideas: The Professor's Guide to Integrating Writing, Critical Thinking, and Active Learning in the Classroom, Jossey-Bass Inc., San Francisco, 1996.

[3] J.G. Kurfiss, Critical thinking: Theory, research, practice, and possibilities, Association for the Study of Higher Education, Washington D.C., 1988. 
Appendix A

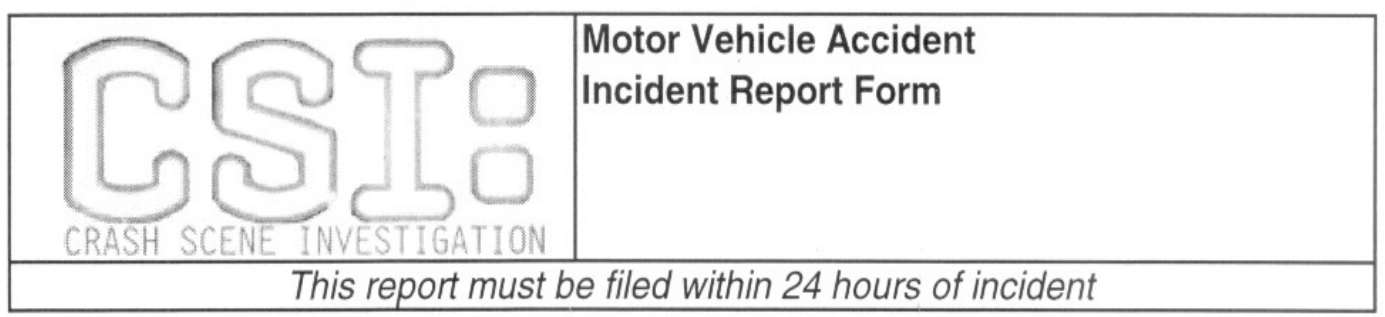

\begin{tabular}{|c|c|c|}
\hline $\begin{array}{l}\text { Date of Accident } \\
\text { moO/day } / 5 \text { year } 03\end{array}$ & $\begin{array}{l}\text { Day of the week } \\
\square \mathrm{M} \square \mathrm{T} \square \mathrm{W} \square \mathrm{R} \square \mathrm{F} \quad \square S a \quad \square \mathrm{Su}\end{array}$ & Hour $23: 30$ \\
\hline
\end{tabular}

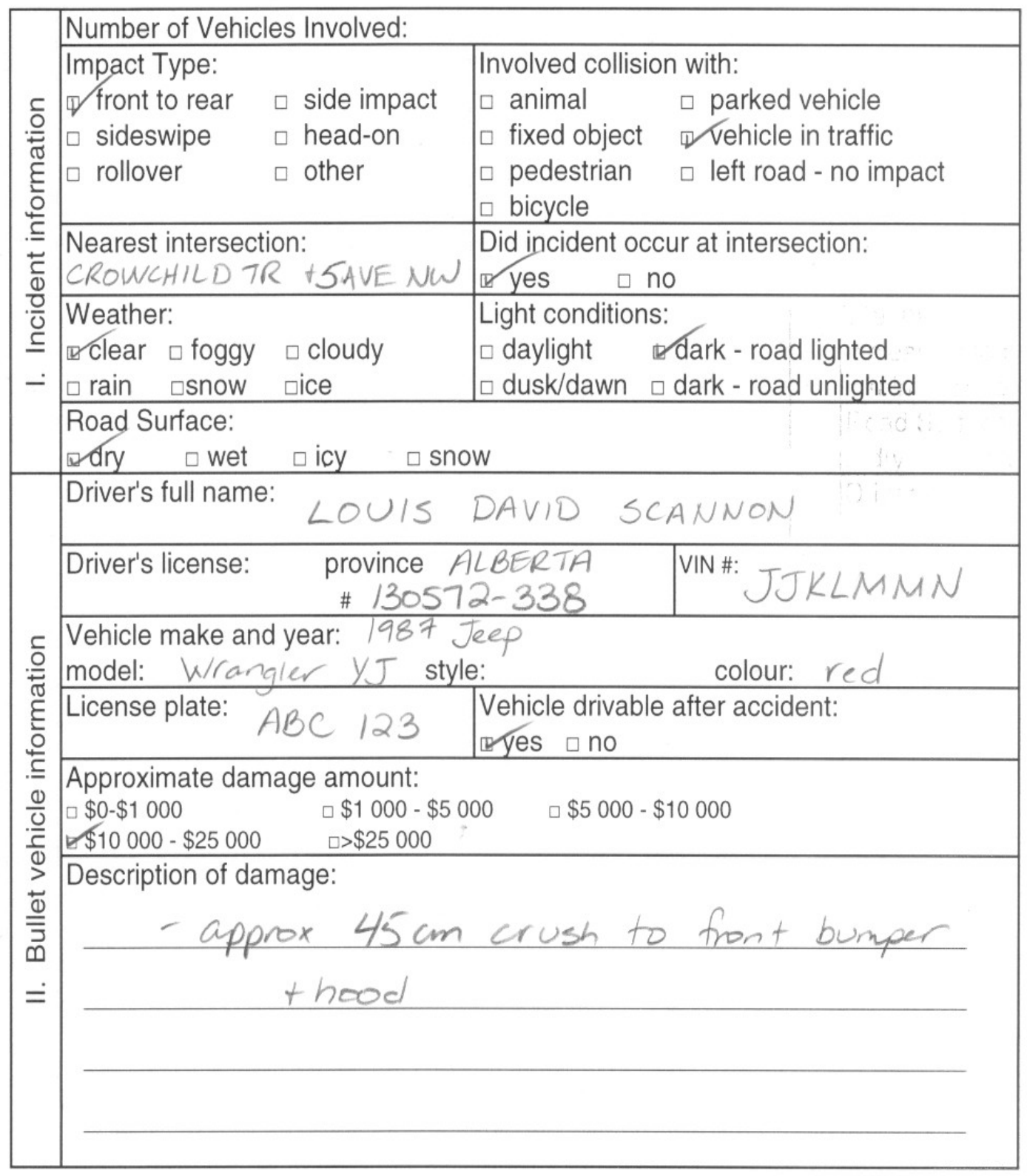




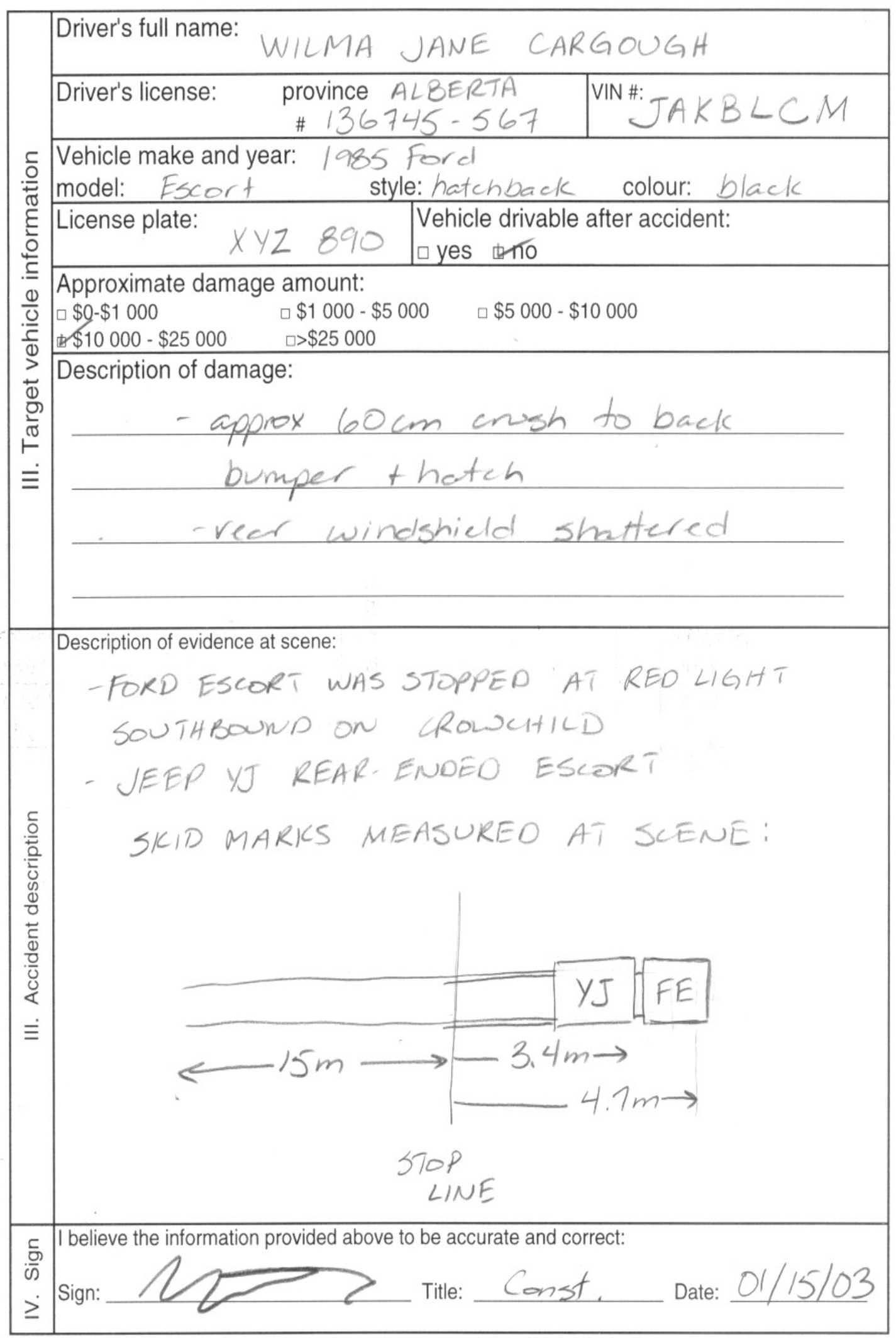

Use additional sheets as necessary if more than one target vehicle. 